\title{
Efficacy of Shockwave Therapy Versus Therapeutic Exercises on Pain and Dynamic Balance in Patients with Plantar Fasciitis
}

\author{
AHMED A. MOHAMED, M.Sc.*; ABDEL RAHMAN CHABARA, Ph.D.*; \\ HAMED M. EL-KHOZAMY, Ph.D.* and AYMAN A. SHAHEEN, M.D.** \\ The Departments of Musculoskeletal Disorders, Faculty of Physical Therapy* and Orthopedic Surgery, Faculty of Medicine**, \\ Cairo University
}

\begin{abstract}
Background: Plantar fasciitis (PF) is a painful disorder of the plantar fascia. It is the most common cause of plantar heel pain and accounts for approximately $11-15 \%$ of foot symptoms presenting to physicians.

Aim of Study: The purpose of this study was to compare the effects of radial shock wave (RSW) alone, therapeutic exercises (stretching and strengthening) alone and RSW combined with therapeutic exercises (stretching and strengthening) on pain severity and dynamic balance in patients with chronic plantar fasciitis (CPF).

Methods: Forty five males and females patients with unilateral CPF participated in this study; their age ranged from 40-50 years. Patients randomly assigned into three groups. Group (A): Received three sessions of RSW therapy. Group (B): Received stretching and strengthening exercises as a home program. Group (C): Received three sessions of RSW therapy (one session every week), stretching and strengthening exercises as a home program. Patients were evaluated for pain and dynamic balance before 1 st session and the end of treatment program.

Results: There was a significant decrease in visual analogue scale (VAS) in favor of group C compared with that of group A and that of group B $(p<0.01)$. Also, there was a significant decrease in VAS in favor of group A compared with that of group B $(p<0.001)$. There was a significant increase in anterior, posterolateral and posteromedial excursion of $Y$ balance test in favor of group A compared with that of group $\mathrm{B}(p<0.05)$; and a significant increase in anterior, posterolateral and posteromedial excursion in favor of group $\mathrm{C}$ compared with that of group B $(p<0.001)$. However; there was no significant difference in anterior, posterolateral and posteromedial excursion between group $\mathrm{A}$ and $\mathrm{C}$ post treatment $(p>0.05)$.
\end{abstract}

Conclusion: RSW therapy only or combined with therapeutic exercises are more effective than therapeutic exercises only on pain and dynamic balance in patients with $\mathrm{CPF}$.

Key Words: Plantar fasciitis - Radial Shockwave - Therapeutic exercises.

Correspondence to: Dr. Ahmed A. Mohamed,

The Orthopedic Department, Faculty of Medicine,

Cairo University

\section{Introduction}

PLANTAR fasciitis (PF) is one of the most common causes of foot pain in adults, with the peak incidence occurs between ages 40 and 60 years in the general population [1]. In up to a third of the cases it may be with heel spurs but whether they have a causal role in the etiology of the disease is still unknown $[2,3]$.

Although several factors have been proposed as causes of PF, biomechanical abnormalities are considered to play a major role in this condition. These include tightness of the Achilles tendon and plantar fascia, reductions in strength in intrinsic foot and ankle muscles, and abnormal foot alignment. With repetitive use of the foot and ankle, the plantar fascia is loaded and can develop chronic degenerative changes with marked thickening and fibrosis within the fascia [4]. Approximately $85 \%$ to $90 \%$ of patients with PF can be successfully treated conservatively. Methods of conservative treatment include rest, nonsteroidal anti-inflammatory drugs, stretching, counter strain technique, orthoses, corticosteroid injections, RSW therapy, and ultrasound (US) therapy. Focused stretching of the Achilles tendon, plantar fascia, and intrinsic muscles of the foot has also been demonstrated to improve pain [5]. Recently RSW has evolved as a safe treatment option for resistant PF. The mechanism of action of RSW therapy is unknown. However it has been thought that faster soft tissue healing, increased blood circulation, inhibition of pain receptors and denervation are responsible for the clinical effects [6]

\section{Patients and Methods}

Forty-five patients with unilateral CPF referred from orthopedic physician participated in this study. 
Patients were subdivided into three groups, each group consisted of 15 patients, group (A) received RSW therapy alone, group (B) received therapeutic (stretching and strengthening) exercises and group (C) received combination of RSW and therapeutic (stretching and strengthening) exercises. They were interviewed and screened based on the following inclusion criteria: Unilateral CPF, Age ranged from 40 to 50 years, symptoms of plantar heel pain lasted more than 3 months.

Exclusion criteria: Patients excluded from the study if they have: History of diabetes, foot deformities, calcaneal fracture, calcaneal cyst, tarsal tunnel syndrome, Rheumatoid arthritis and osteoarthritis, ankle sprain at the time of study, surgery for PF and pregnancy. This study extended from April 2018 to December 2018 at Kasr El-Aini Outpatient Clinic, Cairo, Egypt.

\section{Procedure:}

Evaluation:

Demographic data as date of birth, sex, weight, height, leg-length and duration of symptoms, previous treatments, and affected side were recorded. Evaluation procedures carried out two times:

- Before 1 st session.

- At the end of the study.

\section{1-Assessment of foot pain:}

The patient's pain evaluated using a $10 \mathrm{~cm}$ VAS, with 0 indicating no pain and 10 indicating maximal pain. The outcome measures were determined by measuring heel pain on a $10-\mathrm{cm}$ VAS [7].

\section{2-Assessment of dynamic balance:}

\section{$Y$-Balance test:}

The patient stood on one leg in the center of a grid, with the most distal aspect of the great toe at the starting line. While maintaining single-leg stance, the patient asked to reach with the free limb in the anterior, posteromedial, and posterolateral directions in relation to the stance foot. The maximal reach distance measured by marking the tape measurement. The trial discarded and repeated when the patient failed to maintain unilateral stance, lifted or moved the stance foot from the grid, touched down with the reach foot, or failed to return the reach foot to the starting position. The greatest of 3 trials for each reach direction was used for analysis of the reach distance in each direction. Also, the greatest reach distance from each direction was summed to yield a composite reach distance for analysis of the overall performance on the test [8].
Normalization was performed by dividing each excursion distance by a patient's leg length, and then by multiplying by 100 . Normalized values can thus be viewed as a percentage of excursions distance in relation to a patient's leg length as shown in Fig. (1) [9].

\section{Treatment procedures:}

Group (A):

Radial shockwave therapy (RSW):

The patient placed in prone position, and the therapist clinically located the point of maximum tenderness. The treatment area was prepared with a coupling gel to minimize the loss of shockwave at the interface between applicator tip and skin.

Each patient received 2000 impulses, 3 barenergy level, $15 \mathrm{~mm}$ depth applicator at (frequency= $10 \mathrm{~Hz}$ ) Per session for three weeks with one week interval as shown in Fig. (2) [10]

Group (B):

Patients in this group received therapeutic exercises protocol:

\section{I- Stretching exercises:}

\section{1- Calf stretch:}

Patients received instructions on standing during the Achilles tendon-stretching program. They taught to perform the stretching while standing and leaning onto the wall with the affected leg placed behind the contralateral leg. Patients told to bend the front knee while keeping the back knee straight and the heel firmly on the ground as shown in Fig. (3). The stretching was 5 sets of a 20 -second stretch and a 20-second rest. The stretch was performed twice a day for 5 days per week for 3 consecutive weeks. All patients were required to record their exercise in an exercise log, which was collected at the end of the 3-week intervention. The home program supervised by the therapist through direct contact every week with patients [4] .

\section{2- Plantar fascia stretch:}

Patients were instructed to first cross the affected leg over the contralateral leg in sitting position. Patients were instructed to perform self-stretch for plantar fascia by applying stretching force to the metatarsophalangeal joints on the affected side, pulling the toes upward toward the shin until a stretch was felt in the sole of the foot. Tension in the plantar fascia was palpated with the contralateral hand while performing the stretch. Patients were pulled the heel with the opposite hand and impose an additional longitudinal stretch on the plantar 
fascia as shown in Fig. (4). They was instructed to hold the assigned stretch for ten seconds and to repeat it ten times. The patients were instructed to follow the assigned protocol three times per day [11]

\section{II- Strengthening exercises:}

- Intrinsic foot muscles (IFM):

Patients were instructed to raise the medial longitudinal arch (MLA) of the foot by drawing the metatarsal heads toward the calcaneus without flexing the toes and holding an isometric contraction for 5 seconds during each repetition for 100 repetitions of their prescribed exercise on a daily basis for 3 weeks [12]

\section{Group (C):}

Patients in this group received therapeutic exercises as group B and three RSW sessions as group A.

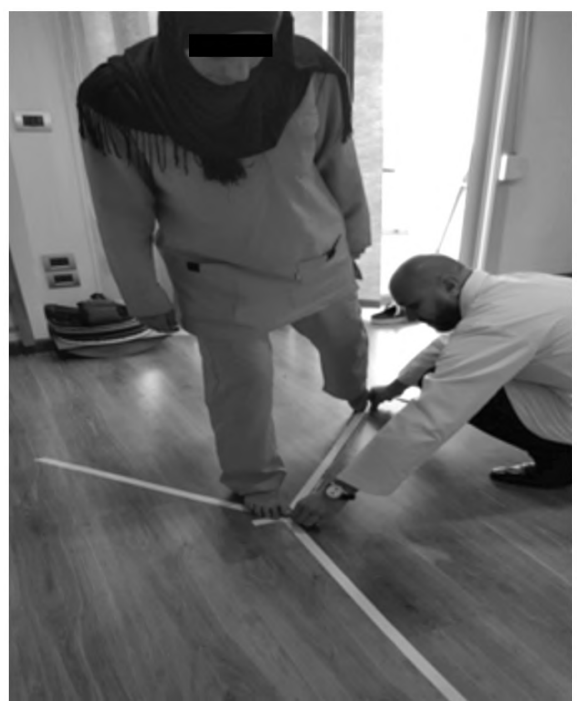

Fig. (1): Postromedial measurement of Y-balance test.

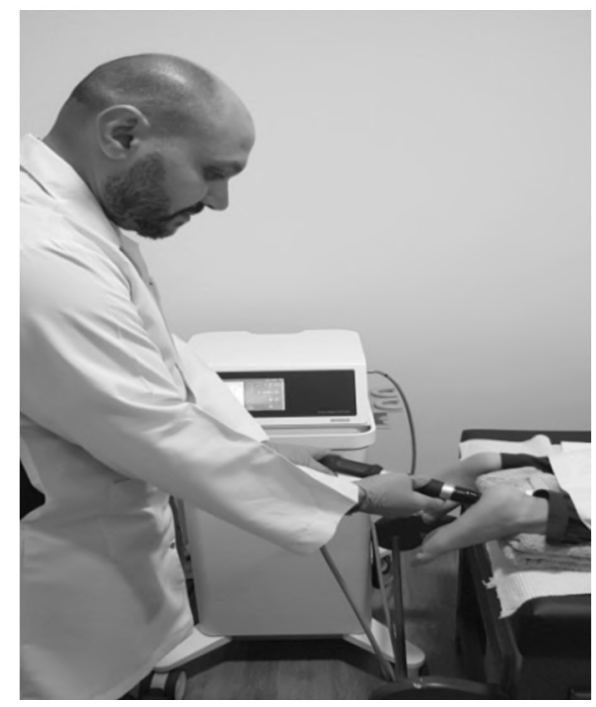

Fig. (2): Radial shock wave therapy.

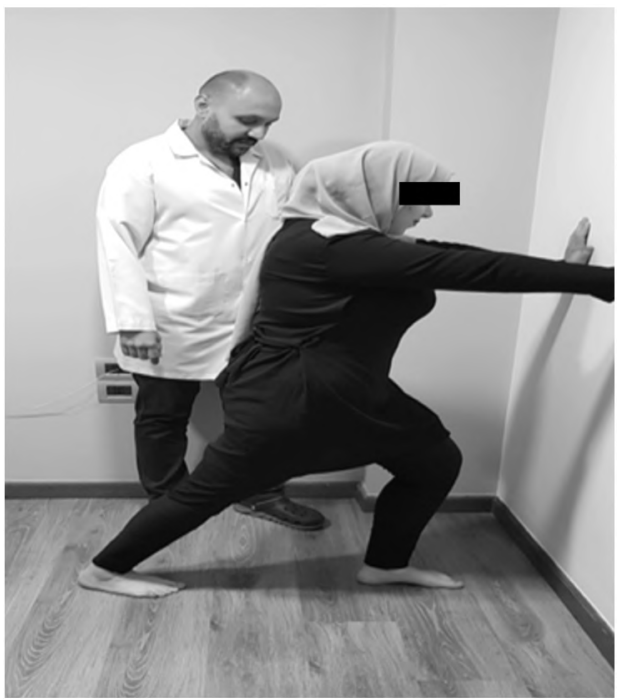

Fig. (3): Calf stretch exercise.

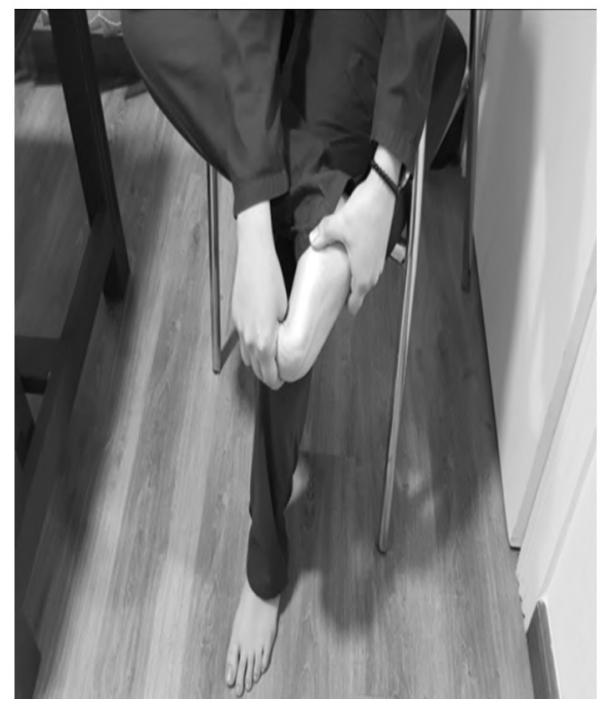

Fig. (4): Plantar fascia stretch exercise.

\section{Results}

Descriptive statistics and ANOVA-test were conducted for comparison of patient's characteristics between groups. Chi-squared test was used for comparison of sex and affected side distribution between groups. Normal distribution of data was checked using the Shapiro-Wilk test for all variables. Levene's test for homogeneity of variances was conducted to test the homogeneity between groups. Mixed MANOVA-test was conducted for comparison of pre and post treatment mean values of VAS, anterior, posterolateral and posteromedial excursion in each group and between groups. Posthoc tests using the Bonferroni correction were carried out for subsequent multiple comparison. The level of significance for all statistical tests was set at $p<0.05$. All statistical analysis was 
conducted through the statistical package for social studies (SPSS) version 19 for windows (IBM SPSS, Chicago, IL, USA).

\section{Patient's characteristics:}

Table (1) showed the mean \pm SD of patient's characteristics of the three groups. There was no significant difference between groups in the mean age, weight, height and body mass index (BMI) $(p>0.05)$. Also, there was no significant difference in the distribution of sex and affected side between groups $(p>0.05)$.

Effect of treatment on VAS, anterior, posterolateral andposteromedial excursion:

Mixed MANOVA revealed that there was a significant interaction of treatment and time (Wilks' Lambda $=0.09 ; \mathrm{F}(8,78)=21.48, p=0.001)$. There was a significant main effect of time (Wilks' Lamb$\mathrm{da}=0.02 ; \mathrm{F}(4,39)=486.92, p=0.001)$. There was a significant main effect of treatment (Wilks' Lamb- $\mathrm{da}=0.29 ; \mathrm{F}(8,78)=8.15, p=0.002)$. Table $(2)$ showed descriptive statistics of VAS, anterior, posterolateral and posteromedial excursion as well as the significant level of comparison between groups and significant level of comparison between pre and post treatment in each group.

Table (1): Basic characteristics of all patients.

\begin{tabular}{lllll}
\hline & \multicolumn{1}{c}{$\begin{array}{c}\text { Group A } \\
\mathrm{X} \pm \mathrm{SD}\end{array}$} & \multicolumn{1}{c}{$\begin{array}{c}\text { Group B } \\
\mathrm{X} \pm \mathrm{SD}\end{array}$} & $\begin{array}{c}\text { Group C } \\
\mathrm{X} \pm \mathrm{SD}\end{array}$ & $\begin{array}{c}p- \\
\text { value }\end{array}$ \\
\hline Age (years) & $45.93 \pm 3.1$ & $45.13 \pm 2.5$ & $44.6 \pm 2.84$ & $0.43^{*}$ \\
Weight $(\mathrm{kg})$ & $85.23 \pm 9.39$ & $84.73 \pm 4.4$ & $84.66 \pm 10.02$ & $0.97^{*}$ \\
Height $(\mathrm{cm})$ & $166.33 \pm 8.48$ & $165.73 \pm 6.82$ & $166.46 \pm 7.95$ & $0.96^{*}$ \\
BMI (kg/m2) & $31.02 \pm 4.58$ & $30.94 \pm 2.41$ & $30.48 \pm 2.08$ & $0.88^{*}$ \\
Sex: & & & & \\
$\quad$ Females & $10(67 \%)$ & $10(67 \%)$ & $9(60 \%)$ & $0.9^{*}$ \\
$\quad$ Males & $5(33 \%)$ & $5(33 \%)$ & $6(40 \%)$ & \\
Affected side: & & & & \\
$\quad$ Right & $7(47 \%)$ & $9(60 \%)$ & $8(53 \%)$ & $0.76^{*}$ \\
$\quad$ Left & $8(53 \%)$ & $6(40 \%)$ & $7(47 \%)$ & \\
\hline
\end{tabular}

$\mathrm{X}$, Mean. SD: Standard deviation. $p$-value, level of significance. *Non-significant.

Table (2): Mean VAS, anterior excursion, posterolateral excursion and posteromedial excursion pre and post treatment of group A, B and C.

\begin{tabular}{|c|c|c|c|c|c|c|}
\hline & \multirow{2}{*}{$\begin{array}{l}\text { Group A } \\
X \pm S D\end{array}$} & \multirow{2}{*}{$\begin{array}{l}\text { Group B } \\
\mathrm{X} \pm \mathrm{SD}\end{array}$} & \multirow{2}{*}{$\begin{array}{l}\text { Group C } \\
X \pm S D\end{array}$} & \multicolumn{3}{|c|}{$p$-value } \\
\hline & & & & A vs B & A vs C & B vs C \\
\hline \multicolumn{7}{|l|}{ VAS: } \\
\hline Pre & $8.98 \pm 0.8$ & $8.79 \pm 1.05$ & $9.05 \pm 0.85$ & $1^{*}$ & $1 *$ & $1 *$ \\
\hline \multirow[t]{2}{*}{ Post } & $3.34 \pm 1.3$ & $5.16 \pm 1.2$ & $1.82 \pm 0.69$ & $0.001 * *$ & $0.002 * *$ & $0.001 * *$ \\
\hline & $p=0.001^{* *}$ & $p=0.001^{* *}$ & $p=0.001 * *$ & & & \\
\hline \multicolumn{7}{|c|}{ Anterior } \\
\hline \multicolumn{7}{|c|}{ excursion (\%): } \\
\hline Pre & $56.32 \pm 4.75$ & $57 \pm 5.43$ & $55.94 \pm 4.96$ & $1^{*}$ & $1 *$ & $1^{*}$ \\
\hline \multirow[t]{2}{*}{ Post } & $66.51 \pm 5.09$ & $61.84 \pm 5.18$ & $68.54 \pm 3.91$ & $0.03 * *$ & $0.75^{*}$ & $0.001 * *$ \\
\hline & $p=0.001 * *$ & $p=0.001^{* *}$ & $p=0.001 * *$ & & & \\
\hline \multicolumn{7}{|c|}{$\begin{array}{l}\text { Posterolateral } \\
\text { excursion (\%) }\end{array}$} \\
\hline Pre & $59.14 \pm 5.97$ & $61.36 \pm 5.2$ & $59.82 \pm 5.66$ & $0.85 *$ & $1^{*}$ & $1^{*}$ \\
\hline \multirow[t]{2}{*}{ Post } & $70.42 \pm 6.41$ & $63.37 \pm 5.76$ & $72.62 \pm 5.86$ & $0.008 * *$ & $0.96^{*}$ & $0.001 * *$ \\
\hline & $p=0.001 * *$ & $p=0.001^{* *}$ & $p=0.001 * *$ & & & \\
\hline \multicolumn{7}{|c|}{$\begin{array}{l}\text { Posteromedial } \\
\text { excursion (\%): }\end{array}$} \\
\hline Pre & $71.13 \pm 7.45$ & $70.33 \pm 5.22$ & $71.94 \pm 7.41$ & $1^{*}$ & $1^{*}$ & $1 *$ \\
\hline \multirow[t]{2}{*}{ Post } & $82.48 \pm 6.58$ & $75.66 \pm 4.92$ & $84.32 \pm 6.8$ & $0.01 *$ & $1^{*}$ & $0.001^{*}$ \\
\hline & $p=0.001^{* *}$ & $p=0.001^{* *}$ & $p=0.001 * *$ & & & \\
\hline
\end{tabular}

\section{Comparisons between groups:}

There was no significant difference between the three groups in all parameters pre-treatment $(p>0.05)$. Post treatment, there was a significant decrease in VAS in favor of group C compared with that of group A and that of group B $(p<0.01)$.
Also, there was a significant decrease in VAS in favor of group A compared with that of group B $(p<0.001)$.

There was a significant increase in anterior, posterolateral and posteromedial excursion in favor of group A compared with that of group B $(p<0.05)$; 
and a significant increase in anterior, posterolateral and posteromedial excursion in favor of group C compared with that of group B $(p<0.001)$. However; there was no significant difference in anterior, posterolateral and posteromedial excursion between group $\mathrm{A}$ and $\mathrm{C}$ post treatment $(p>0.05)$.

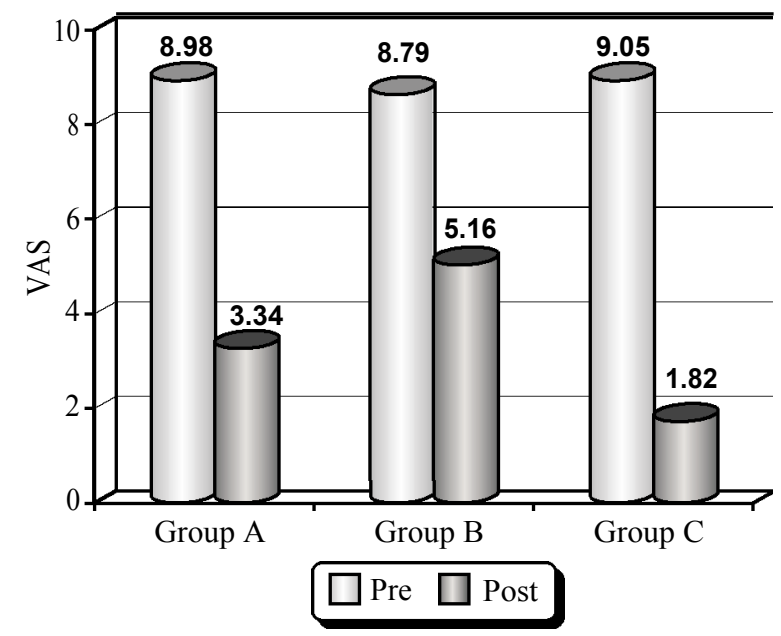

Fig. (5): Mean VAS pre and post treatment of group A, B, C.

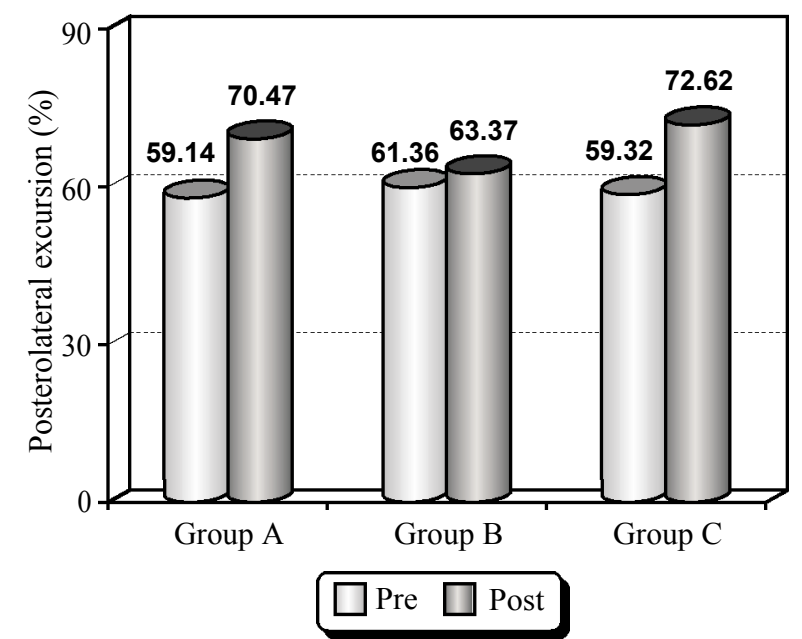

Fig. (7): Mean posterolateral excursion pre and post treatment of group A, B, C.

\section{Discussion}

Regarding the pain severity the results of the current study showed that both groups A and C who received (combination therapy of RSW and therapeutic exercises or RSW alone) improved significantly than group B and these results came in agreement with results of (Jan et al., 2015) [13] who tested the null hypothesis of no difference of RSW therapy or RSW therapy combined with

\section{Comparison within group:}

Comparison between pre and post treatment in the three group revealed a significant decrease in VAS and a significant increase in anterior excursion, posterolateral and posteromedial excursion post treatment compared with that pre-treatment in $(p<0.001)$ (Figs. 5-8).

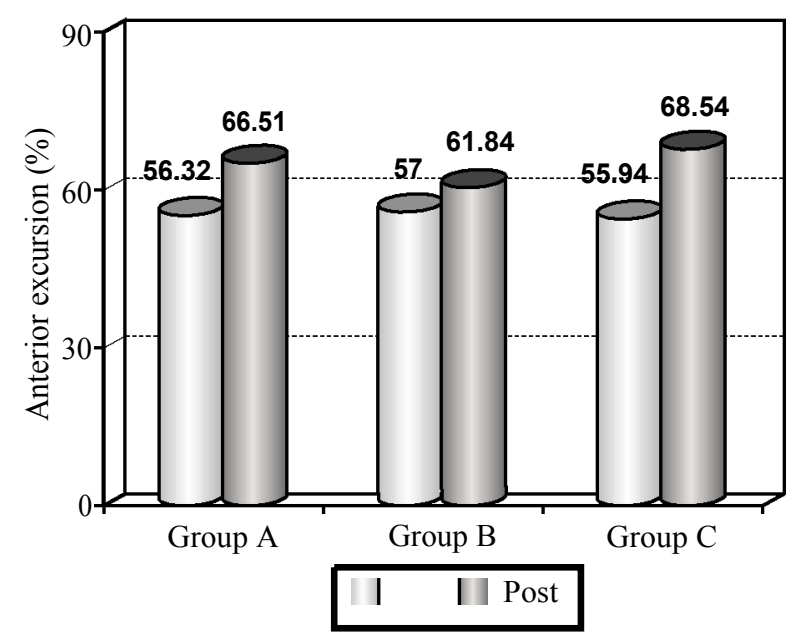

Fig. (6): Mean anterior excursion pre and post treatment of group $\mathrm{A}, \mathrm{B}, \mathrm{C}$.

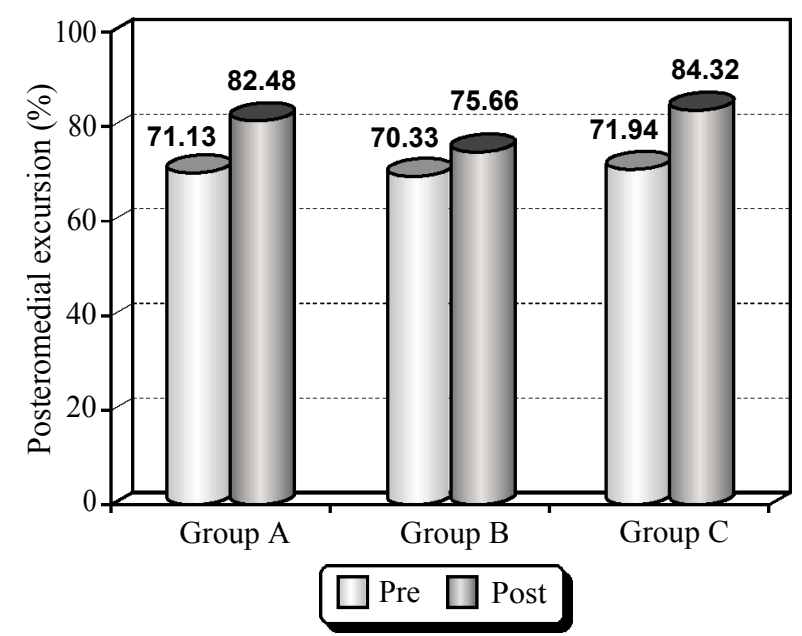

Fig. (8): Mean posteromedial excursion pre and post treatment of group A, B, C.

plantar fascia-specific stretching for patients who had unilateral PF. One hundred and fifty-two patients with CPF were assigned into two groups. One group received three RSW therapy sessions, the other group received RSW with an eight-week plantar fascia-specific stretching program. They concluded that a program of manual stretching exercises specific to the plantar fascia in combination with RSW therapy is more efficient than RSW therapy alone for the treatment of CPF. 
Clinically, five randomized controlled studies showed that RSW therapy when applied repetitively directed to the tender point at the medial calcaneal tubercle leads to significant and persistent improvement of plantar fasciopathy symptoms. All five trials concluded that RSW therapy was efficient in the treatment of CPF [14-18].

Another study reported that RSW therapy is effective and safe for the management of CPF. Fifty patients with CPF were randomly assigned to either two sessions of RSW therapy (one session per week) or to placebo treatment. They concluded that the use of RSW therapy in patients with CPF was effective and safe, leading to a significant, long-term reduction in pain (Mahmoud et al., 2017) [19].

Gerdesmeyer et al., 2008 [20]. Studied the effect of RSW therapy and placebo in the treatment of CPF on two hundred fifty one patients. RSW therapy or placebo administered in 3 sessions, each 2 weeks apart. The authors concluded that RSW therapy significantly reduced pain, improved function and quality of life in patients with CPF.

In contrast to our study (Jan et Al., 2010) [21] showed that a program of manual stretching exercises specific to the plantar fascia is superior to RSW therapy for the treatment of proximal PF. One hundred and two patients with acute PF were randomly assigned to perform an eight week plantar fascia-specific stretching program (Group I, $n=54$ ) or to receive RSW therapy without local anesthesia, administered weekly for three weeks (Group II, $\mathrm{n}=48$ ). The difference between our results and the results of study carried out by Jane et al., may be attributed to chronicity of patients (the current study applied on CPF and the other study applied on acute patients), parameters used of RSW (Jan et al., used 4 bar of RSW but the current study used 3 bar), period of time (they conducted the study in 8 weeks but our study conducted on 3 weeks) and type of exercises.

Another study by (Greve's et al., 2009) [22] compared the effect of RSW and conventional physiotherapy on CPF. Thirty-two patients with CPF were randomly assigned into two groups. Group I underwent 10 physiotherapy sessions of US and exercises. Group II was treated with RSW. Sessions were performed once per week for total of three sessions. Evaluation carried out after three months showed that there was no significant difference between RSW therapy and conventional physiotherapy. The difference between results of current study and (Greve's et al., 2009) may be due to the kind of strengthening exercise we applied (IFM) which reported to be weak in CPF and the exercises they applied on tibialis anterior which is considered to be an extrinsic ankle muscles. The stretched exercises in the current study applied on plantar fascia and calf muscles which explain the rapid effect of the exercises on PF.

Marcus et al., 2013 [23] compared RSW treatment with conventional physiotherapy for CPF after 12 months of follow-up, forty patients were divided randomly into two treatment groups: Group 1 , with 20 patients who underwent ten physiotherapy sessions comprising ultrasound, kinesiotherapy and guidance for home-based stretching; and group 2 , with 20 patients who underwent three applications of RSW, once a week, and guidance for homebased stretching. At the 12-month follow-up, both treatments were effective for improving pain and functional ability among the patients with PF.

Regarding the dynamic balance our results showed a significant increase in anterior, posterolateral and posteromedial excursion in favor of groups $\mathrm{A}$ and $\mathrm{C}$ which came in agreement with (Scott et al., 2012) [12] who tested the effect of two different types of IFM training on the static and dynamic balance performance. Also study done on 54 female patients with unilateral CPF were randomly assigned into two groups and one control group. All groups performed home exercises. In addition, the first group received three RSW and the second group received seven sessions of US treatment. Static and dynamic equilibrium were evaluated. Patients were evaluated before and after four weeks of treatment. The results of this study concluded that US and RSW were effective methods to increase functionality in CPF especially when combined with exercises (Bihter et al., 2017) [24].

Findings of the present study disagree with the work of (Heinz et al., 2010) [10]. Who found that focused shockwave therapy (FSW) was superior to RSW in CPF. Thirty nine patients suffering from CPF were randomized in two groups. Treatment was performed in three sessions. Once a week 2000 impulses of RSW $\left(0.17 \mathrm{~mJ} / \mathrm{mm}^{2}\right)$ or FSW $(0.20 \mathrm{~mJ} /$ $\mathrm{mm}^{2}$ ) were applied.

\section{Conclusion:}

Based on the scope and findings of this study, it could be concluded that RSW alone or combined with therapeutic exercises are more effective than therapeutic exercises only on relieving pain and improving dynamic balance in patients with $\mathrm{CPF}$. 


\section{References}

1- TU P. and BYTOMSKI J.R.: Diagnosis of heel pain. Am. Fam. Physician., 84: 909-916, 2011.

2- LABOVITZ J.M., YU J. and KIM C.: The role of hamstring tightness in plantar fasciitis. Foot Ankle Spec., 4: 141149, 2011.

3- LEVY J.C., MIZEL M.S., CLIFFORD P.D. and TEMPLE H.T.: Value of radiographs in the initial evaluation of non-traumatic adult heel pain. Foot Ankle Int., 27:427430, 2006

4- PHOOMCHAI E., ROTSALAI K. and NITHIMA P. Effectiveness of the Simultaneous Stretching of the Achilles Tendon and Plantar Fascia in Individuals With Plantar Fasciitis. Foot \& Ankle International, 39 (1): 75-82, 2018

5- JOHN V. THOMPSON, SUNDEEP S. SAINI, CHRISTOPHER W. and JOSEPH N. DANIEL: Diagnosis and Management of Plantar Fasciitis. The Journal of the American Osteopathic Association, 12: 900-906, 2014.

6- JUSTYNA W, JUSTYNA P.B., ANNA S'. and JULIAN S.: Extracorporeal shock wave therapy in the treatment of plantar fasciitis. Medical Review, 14 (4): 465-472, 2016.

7- JENSEN M., CHEN C. and BRUGGER A.: Interpretation of visual analog Scale ratings and change scores: A reanalysis of two clinical trials of postoperative pain. J. Pain, 4 (7): 407-414.

8- PHILLIP J. PLISKY, MITCHELL J. RAUH, THOMAS W. KAMINSK and FRANK B.: Star Excursion Balance Test as a Predictor of Lower Extremity Injury in High School Basketball Players. J. Orthop. Sports. Phys. Ther. 36: (12): 911-919, 2006.

9- PHILLIP A., GRIBBLE and JAY HERTEl: Considerations for normalizing measures of the star excursion balance test. Measurent in Physical Education and Exercise Science, 7 (2): 89-100, 2003.

10- HEINZ LOHRER, TANJA NAUCK, NADJA V. DORNLANGE, JAKOB SCHOLL and JOHANNES C. VESTER: Comparison of radial versus focused extracorporeal shock waves in plantar fasciitis using functional measures. Foot \& Ankle International, 31: 1-9, 2010.

11- BENEDICT F. DIGIOVANNI, DEBORAH A. NAWOCZENSKI, DANIEL P. MALAY, PETRA A. GRACI, TARYN T. WILLIAMS, GREGORY E. WILDING and JUDITH F. BAUMHAUER: Plantar fascia-specific stretching exercise improves outcomes in patients with chronic plantar fasciitis. The Journal of Bone \& Joint Surgery, 88: 1775-1781, 2006.

12- SCOTT K. LYNN, RICARDO A. PADILLA and KAVIN K.W. TSANG: Differences in Static- and Dynamic-Balance Task Performance after 4 Weeks of Intrinsic-Foot-Muscle Training: The Short-Foot Exercise versus the Towel-Cur 1 Exercise. Journal of Sport Rehabilitation, 21: 327-333, 2012.

13- JAN D. ROMPE A., JOHN FURIA B., ANGELO CACCHIO C., CHRISTOPH SCHMITZ D. and NICOLA MAFFULLI RADIAL: Shock wave treatment alone is less efficient than radial shock wave treatment combined with tissue-specific plantar fascia stretching in patient with chronic plantar heel pain. International Journal of Surgery, 24: 135-142.2015.

14- J.N.C. DIZON, C. GONZALEZ-SUAREZ, M.T.G. ZAMORA and E.D.V. GAMBITO.: Effectiveness of extracorporeal shock wave therapy in chronic plantar fasciitis. A metaanalysis, Am. J. Phys. Med. Rehabil, 92: 606-620, 2013.

15- C. SCHMITZ, N.B.M. CSASZAR, J.D. ROMPE, H. CHAVES and J.P. FURIA: Treatment of chronic plantar fasciopathy with extracorporeal shock waves (review). J. Orthop. Surg. Res., 8: 31-41.

16- L. GERDESMEYER, C. FREY, J. VESTER, M. MAIER, L. WEIL J.R., L. WEIL S.R., M. RUSSLIES, J. STIENSTRA, B. SCURRAN, K. FEDDER, P. DIEHL, H. LOHRER, M. HENNE and H. GOLLWITZER: Radial extracorporeal shock wave therapy is safe and effective in the treatment of chronic recalcitrant plantar fasciitis: Results of a confirmatory randomized placebo-controlled multicenter study. Am. J. Sports Med., 36: 2100-2109.

17- M.I. IBRAHIM, R.A. DONATELLI, C. SCHMITZ, M.A HELLMAN and F. BUXBAUM.: Chronic plantar fasciitis treated with two sessions of radial extracorporeal shock wave therapy. Foot Ankle Int., 31: 391-397, 2010.

18-W. MARKS, A. JACKIEWICZ, Z. WITKOWSKI, J. KOT, W. DEJA and J. LASEK: Extracorporeal shock-wave therapy (ESWT) with a new-generation pneumatic device in the treatment of heel pain: A double blind randomised controlled trial, Acta. Orthop. Belg., 74: 98-101, 2008.

19- MAHMOUD I. IBRAHIM, ROBERT A. DONATELLI, MADELEINE HELLMAN, AHMED Z. HUSSEIN, JOHN P. FURIA and CHRISTOPH SCHMITZ: Long-Term results of radial extracorporeal shock wave treatment for chronic plantar fasciopathy: A prospective, Randomized, placebo-controlled trial with two years follow-up. Journal of Orthopaedic Research, 7: 1532-158, 2017.

20- GERDESMEYER L., FREY C., VESTER J., et al.: Radia Extracorporeal Shock Wave Therapy Is Safe and Effective in the Treatment of Chronic Recalcitrant Plantar Fasciitis. Am. J. Sports. Med., 35 (11): 2100-2109, 2008.

21- JAN D. ROMPE, ANGELO CACCHIO, LOWELL WEIL JR., JOHN P. FURIA, JOACHIM HAIST, VOLKER REINERS, CHRISTOPH SCHMITZ and NICOLA MAFFULLI: Plantar fascia-specific stretching versus radial shock-wave therapy as initial treatment of plantar fasciopathy. J. Bone. Joint. Surg. Am., 92: 2514-22, 2010.

22- GREVE J., GRECCO M. and SANTOS-SILVA P.: Comparison of radial shockwaves and conventional physiotherapy for treating plantar fasciitis. Clinics, 64 (2): 97103,2009

23- MARCUS VINICIUS GRECCO, GUILHERME CARLOS BRECH and JU'LIA MARIA D'ANDREA GREVE: Oneyear treatment follow-up of plantar fasciitis: Radial shockwaves vs. conventional physiotherapy. Clinics, 68 (8): 1089-1095, 2013.

24- BIHTER A., NEZIRE K., NURAR K. and YAVUZ Y. Comparison of the acute effect of radial shock wave therapy and ultrasound therapy in the treatment of plantar fasciitis: A randomised controlled study. Pain Medicine, 18: 2443-2452, 2017. 


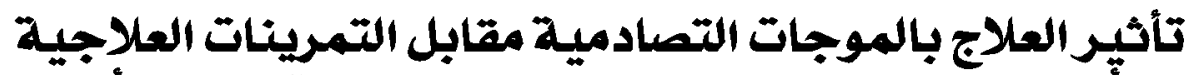

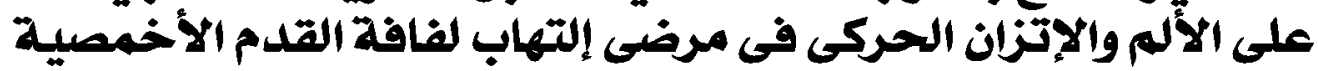

الغرض من الدراسة التحقق من تأثير الموجات التصادمية منفردة أو التمارين العلاجية منفردة أو الموجات التصادمية والتمارين العلاجية مجمعة على حالات إلتهابات لفافة القدم الأخمصية.

تم إجراء الدراسة على مدار سبع شهود في العيادة الخارجية فى القصر العينى بالقاهرة - مصر وقد أشتملت الدراسة على خمس وأربعصن

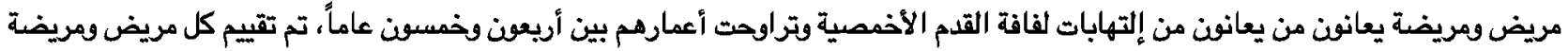

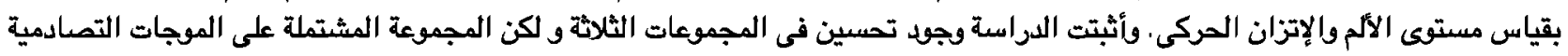

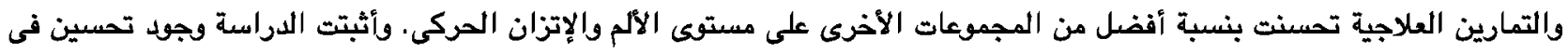

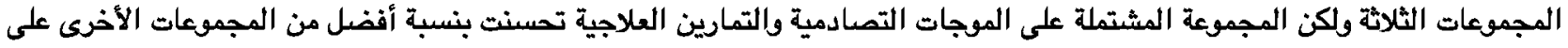
مستوى الألم والإتزان الصركى. المحتوى: بناء على تتائج الدراسة لقد أثتبت أن الموجات التصادمية والتمارين العلاجية لها تأثير أفضل على تخفيف الآلم وتحسين الأتزان الحركى على مرضى إلتهاب لفافة القدم الأخمصية. 